\title{
Transcription factors FabR and FadR regulate both aerobic and anaerobic pathways for unsaturated fatty acid biosynthesis in Shewanella oneidensis
}

\section{Qixia Luo, Miaomiao Shi, Yedan Ren and Haichun Gao*}

Institute of Microbiology and College of Life Sciences, Zhejiang University, Hangzhou, China

\section{Edited by:}

Yi-Cheng Sun, Chinese Academy of Medical Sciences and Peking Union Medical College, China

Reviewed by:

Liang Shi, Wright State University, USA

Pendru Raghunath, Dr. VRK

Women's Medical College, India

*Correspondence:

Haichun Gao, Institute of

Microbiology and College of Life

Sciences, Zhejiang University, 866

Yuhangtang Road, Hangzhou,

Zhejiang 310058, China

e-mail: haichung@zju.edu.cn
As genes for type II fatty acid synthesis are essential to the growth of Escherichia coli, its sole (anaerobic) pathway has significant potential as a target for novel antibacterial drug, and has been extensively studied. Despite this, we still know surprisingly little about fatty acid synthesis in bacteria because this anaerobic pathway in fact is not widely distributed. In this study, we show a novel model of unsaturated fatty acid (UFA) synthesis in Shewanella, emerging human pathogens in addition to well-known metal reducers. We identify both anaerobic and aerobic UFA biosynthesis pathways in the representative species, $S$. oneidensis. Uniquely, the bacterium also contains two regulators FabR and FadR, whose counterparts in other bacteria control the anaerobic pathway. However, we show that in $S$. oneidensis these two regulators are involved in regulation of both pathways, in either direct or indirect manner. Overall, our results indicate that the UFA biosynthesis and its regulation are far more complex than previously expected, and $S$. oneidensis serves as a good research model for further work.

Keywords: UFAs, biosynthesis, regulation, Shewanella, FadR

\section{INTRODUCTION}

Bacterial membrane, an essential structure involved in almost every aspect of bacterial growth and metabolism, generally lacks sterols and contains mainly phospholipids such as phosphatidylethanolamine (PtdEtn) and phosphatidylglycerol (PtdGro) (Zhang and Rock, 2008). To support normal structure and functions, membranes are required to maintain the appropriate fluidity, which is determined largely by the composition of fatty acids attached to membrane phospholipids, including straight-chain unsaturated fatty acids (UFAs), saturated fatty acids (SFAs), and branched-chain fatty acids (BCFAs) (Campbell and Cronan, 2001; Mendoza, 2014). As these fatty acids are required for bacterial survival, their biosynthesis pathway has been an important target for the development of novel antimicrobials in recent years, even though microbes are capable of incorporating environmental fatty acids into phospholipids (Campbell and Cronan, 2001; Parsons and Rock, 2011).

In bacteria, two pathways have been identified for biosynthesis of UFAs, distinct from each other in whether oxygen is involved (Altabe et al., 2013). The anaerobic pathway comprises, as best illustrated in Escherichia coli, a group of highly conserved proteins known as the type II fatty acid synthase (FAS II) system (Campbell and Cronan, 2001). During biosynthesis, the double bond is introduced at the C10 level by FabA, which catalyzes the dehydration and isomerization reactions to produce cis-3-decenoyl-ACP from standard biosynthetic intermediate, the trans-2-decenoyl thioester of acyl carrier protein (ACP) (Cronan et al., 1969). FabB, a $\beta$-ketoacyl-ACP synthase, is required to elongate the cis-3-decenoyl-ACP and its activity is the primary factor in determining cellular UFA content (Cronan, 2006). However, FabA and FabB in fact are not widely distributed in anaerobic bacteria that produce UFAs; as a consequence, a similar pathway with functional replacements of E. coli FabA and FabB is evolved (Marrakchi et al., 2002; Wang and Cronan, 2004). The aerobic pathway employs iron-containing transmembrane proteins to desaturate the fully elongated acyl chains, such as Des in Bacillus subtilis (Aguilar et al., 1998). While bacteria in which the subject has been investigated so far are generally equipped with either pathway for UFA biosynthesis, Pseudomonas aeruginosa has both, with two independent desaturases DesA and DesB (Zhu et al., 2006).

Given its critical role in maintaining membrane integrity and proper fluidity, it is conceivable that biosynthesis of fatty acids is tightly regulated in response to changes in environment. In E. coli, the most prominent control resides at the transcriptional level, which depends on FadR (fatty acid degradation regulator) and FabR (fatty acid biosynthesis regulator) (Fujita et al., 2007; Zhu et al., 2009). FadR, a regulator of the GntR family, principally functions as a global regulator of both UFA synthesis and the $\beta$-oxidative utilization of fatty acids as a carbon source and is antagonized by long-chain acyl-CoAs (Henry and Cronan, 1992; Cronan and Subrahmanyam, 1998). Its regulation on UFAs is realized by activating the $f a b A$ and $f a b B$ genes and by repressing the $\beta$-oxidation operons. FabR, discovered much later (McCue et al., 2001), is a regulator of the TetR family, which acts as a repressor for the $f a b A$ and $f a b B$ genes in the presence of UFAs (Zhu et al., 2009; Feng and Cronan, 2011). In the case of aerobic desaturases, information about their 
regulation is limited. In B. subtilis, a two-component system, DesK-DesR, mediates expression of the des gene in response to a decrease in environmental temperature (Cybulski et al., 2010). In $P$. aeruginosa, the des $B$ gene is regulated by an E. coli FabR homolog DesT, which senses the physical properties of the cellular acyl-CoA pool, while regulation of the desA gene remains unknown (Zhang et al., 2007; Miller et al., 2010). Surprisingly, an E. coli FadR appears to be missing in $P$. aeruginosa given that it contains up to $27 \mathrm{GntR}$ homologs (Choi and Schweizer, 2005).

Shewanella species are widely distributed in environments, and are well known for their versatile respiration capabilities, which are exploited for bioremediation of toxic elements and serving as microbial fuel cells (Fredrickson et al., 2008). In contrast to this beneficial role, Shewanellae are increasingly being implicated as human pathogens in persons exposed through occupational or recreational activities to marine niches where these species thrive (Janda and Abbott, 2014). Particularly, some Shewanella have been identified as gut pathogen, causing food poisoning by presumably producing tetrodotoxin, a potent neurotoxin that selectively blocks voltage-sensitive $\mathrm{Na}^{+}$ion channels (Auawithoothij and Noomhorm, 2012; Moczydlowski, 2013; Wang et al., 2013). As the membrane composition of Shewanella is, at least in part, accountable for their widely distribution and unique physiological characteristics, in this study we took on to investigate the UFA biosynthesis and regulation in the intensively studied representative, $S$. oneidensis. We show that $S$. oneidensis possesses a FabA-based anaerobic UFA synthesis pathway and a single desaturase DesA for aerobic UFA biosynthesis, as well as two wellestablished regulators, FabR and FadR. Our results describe that the anaerobic pathway plays a predominant role in UFA synthesis and the aerobic pathway becomes active in the absence of FabA. We further show that FadR directly activates the anaerobic pathway, while FabR acts as a repressor for both pathways. In short, for the first time we provide insights into the regulation of UFA homeostasis in a bacterium equipped not only with both anaerobic and anaerobic pathways but also with FadR and FabR regulators.

\section{METHODS AND MATERIALS}

\section{BACTERIAL STRAINS, PLASMIDS, AND CULTURE CONDITIONS}

Bacterial strains and plasmids used in this study are listed in Table 1 and sequences of primers used are given in Table S1. All chemicals were acquired from Sigma Co. (Shanghai, China) unless specifically noted. For genetic manipulation, E. coli and $S$. oneidensis strains under aerobic conditions were grown in Luria-Bertani (LB) medium at 37 and $30^{\circ} \mathrm{C}$, respectively. When needed, the growth medium was supplemented with chemicals at the following concentrations: 2,6-diaminopimelic acid (DAP), $0.3 \mathrm{mM}$; ampicillin, $50 \mu \mathrm{g} / \mathrm{ml}$; kanamycin, $50 \mu \mathrm{g} / \mathrm{ml}$; and gentamycin, $15 \mu \mathrm{g} / \mathrm{ml}$.

For physiological characterization, both LB and M1-defined medium containing $0.02 \%(\mathrm{w} / \mathrm{v})$ of vitamin free Casamino Acids and $15 \mathrm{mM}$ lactate as the electron donor were used in this study and consistent results were obtained (Gao et al., 2008a). Anaerobic growth was supported by $20 \mathrm{mM}$ fumarate as the electron acceptor. Fresh medium was inoculated with overnight
Table 1 | Strains and plasmids used in this study.

\begin{tabular}{|c|c|c|}
\hline Strain or plasmid & Relevant characteristics & Sources or references \\
\hline \multicolumn{3}{|l|}{ E. COLI STRAINS } \\
\hline $\mathrm{DH} 5 \alpha$ & Host strain for plasmids & Lab stock \\
\hline WM3064 & $\begin{array}{l}\text { Donor strain for conjugation; } \\
\Delta d a p A\end{array}$ & W. Metcalf, UIUC \\
\hline XL1-Blue MRF'Kan & $\begin{array}{l}\text { Recipient strain for } \\
\text { one-hybrid system }\end{array}$ & Stratagene \\
\hline \multicolumn{3}{|c|}{ S. ONEIDENSIS STRAINS } \\
\hline MR-1 & Wild-type & ATCC 700550 \\
\hline HG0197 & $\begin{array}{l}\Delta \text { desA derived from MR-1 } \\
\text { As MR-1 plus } \Delta \text { katG-1 }\end{array}$ & This study \\
\hline HG0198 & $\Delta$ fabR derived from MR-1 & This study \\
\hline HG1856 & $\triangle$ fabA derived from MR-1 & This study \\
\hline HG2885 & $\Delta$ fadR derived from MR-1 & This study \\
\hline HG0197-1856 & $\begin{array}{l}\Delta \text { fabA } \Delta \text { desA derived } \\
\text { from MR-1 }\end{array}$ & This study \\
\hline \multicolumn{3}{|l|}{ PLASMIDS } \\
\hline pHGM01 & $\begin{array}{l}\text { Suicide vector for mutant } \\
\text { construction }\end{array}$ & Jin et al., 2013 \\
\hline pHG101 & $\begin{array}{l}\text { Promoterless vector for } \\
\text { complementation }\end{array}$ & Wu et al., 2011 \\
\hline pHG102 & pHG101 containing $P_{\text {ArcA }}$ & Wu et al., 2011 \\
\hline pHGEI01 & $\begin{array}{l}\text { Integrative lacZ reporter } \\
\text { vector }\end{array}$ & Fu et al., 2014a \\
\hline pBBR-Cre & $\begin{array}{l}\text { Helper plasmid for antibiotic } \\
\text { marker removal }\end{array}$ & Fu et al., 2013 \\
\hline $\mathrm{pBXcmT}$ & $\mathrm{B} 1 \mathrm{H}$ bait vector & Guo et al., 2009 \\
\hline pTRG & $\mathrm{B} 1 \mathrm{H}$ target vector & Stratagene \\
\hline pTP247 & $\begin{array}{l}\text { His }_{6} \text {-tag expression Vector, } \\
\mathrm{Ap}^{\mathrm{R}}\end{array}$ & Gao et al., 2008a \\
\hline
\end{tabular}

cultures grown from a single colony by 1:100 dilution, and growth under aerobic and anaerobic conditions was determined by recording the optical density of cultures at $600 \mathrm{~nm}\left(\mathrm{OD}_{600}\right)$. For cultures with fatty acid additions, which interfere with OD readings, growth was monitored by photographing colonies on plates. Mid-log-phase $\left(\sim 0.4\right.$ of $\mathrm{OD}_{600}$, unless mentioned otherwise) cells were properly diluted, plated on solid agar plates containing a paper disk of $6 \mathrm{~mm}$ in diameter as the size reference, and incubated at $30^{\circ} \mathrm{C}$.

\section{IN-FRAME DELETION MUTAGENESIS AND COMPLEMENTATION}

In frame deletion strains were constructed according to the att-based Fusion PCR method described previously (Jin et al., 2013). In brief, two fragments flanking the gene of interest were amplified with primers containing $a t t B$ and the gene specific sequence, and then joined by a second round of PCR. The fusion fragment was introduced into pHGM01 by site-specific recombination using the BP Clonase (Invitrogen) and maintained in E. coli WM3064. The resulting mutagenesis vector was then transferred from E. coli into S. oneidensis by conjugation. Integration of the mutagenesis construct into the chromosome was selected by gentamycin resistance and confirmed by PCR. Verified trans-conjugants were grown in LB broth in the absence of $\mathrm{NaCl}$ and plated on $\mathrm{LB}$ supplemented with 
$10 \%$ sucrose. Gentamycin-sensitive and sucrose-resistant colonies were screened by PCR for the intended deletion. The deleted mutants were then verified by sequencing.

Plasmids pHG101 and pHG102 were used in genetic complementation of mutants (Wu et al., 2011). For complementation of genes adjacent to their promoter, a fragment containing the gene of interest and its native promoter was generated by PCR and cloned into pHG101. For the rest genes, the gene of interest was amplified and inserted into MCS of pHG102 under the control of the $\operatorname{arcA}$ promoter, which is constitutively active (Gao et al., 2010a). After verified by sequencing, the vectors were introduced into the relevant mutants for phenotypic assays.

\section{EXPRESSION ASSAYS}

Expression of genes of interest was assessed using an integrative lacZ-reporter system (Fu et al., 2014a). Based on the promoter prediction, fragments of $\sim 300$ bp covering the promoter sequences were cloned into the reporter vector pHGEI01 to generate transcriptional fusions. The resultant vectors were then verified by sequencing and then transferred into relevant strains by conjugation. To eliminate the antibiotic marker, helper plasmid pBBR-Cre was transferred into the strains carrying a correctly integrated construct (Fu et al., 2013). Mid-log phase cultures were harvested, properly aliquotted, and subjected to $\beta$-Galactosidase activity assay as described before (Fu et al., 2014a).

Expression of genes of interest was also assessed using quantitative reverse-transcription PCR (qRT-PCR). Cells of the midlog phase were harvested by centrifugation and total RNA was isolated using RNeasy Mini Kit (QIAGEN) according to the manufacturer's instructions. The analysis was carried out with an ABI7300 96-well qRT-PCR system (Applied Biosystems) as described previously (Yuan et al., 2011).

\section{FATTY ACID COMPOSITIONAL ANALYSIS}

To determine fatty acid composition, cultures of the mid-log phase grown in LB medium were collected by centrifugation, properly aliquotted, and subjected to total cellular lipid extraction as described before (Bligh and Dyer, 1959). The fatty acid methyl esters (FAMEs) were prepared by trans-esterification with $0.5 \mathrm{M}$ sodium methoxide in methanol and identified using gas chromatograph-mass spectroscopy (GC-MS) (Focus GC-DSQ II) on a capillary column ( $30 \mathrm{~mm}$ by $0.25 \mathrm{~mm}$ in diameter) (Zhang et al., 2002). Helium at $1 \mathrm{ml} / \mathrm{min}$ was used as the carrier gas, and the column temperature was programmed to rise by $4^{\circ} \mathrm{C} / \mathrm{min}$ from 140 to $170^{\circ} \mathrm{C}$, and then $3.5^{\circ} \mathrm{C} / \mathrm{min}$ from 170 to $240^{\circ} \mathrm{C}$ for $12.5 \mathrm{~min}$.

\section{BACTERIAL ONE-HYBRID (B1H) ASSAY}

$\mathrm{B} 1 \mathrm{H}$ system was utilized to investigate DNA-protein interaction in vivo in E. coli cells as described previously (Guo et al., 2009; Jiang et al., 2014). Plasmids were constructed by cloning the "bait" promoter region DNA and "target" regulators into the $\mathrm{pBXcmT}$ and PTRG vectors, respectively. After verified by sequencing, the resultant plasmids were used to co-transform BacterioMatch II Validation Reporter Competent cells on M9 salt agar plates containing $25 \mathrm{mg} / \mathrm{ml}$ chloramphenicol and $12.5 \mathrm{mg} / \mathrm{ml}$ tetracycline with or without 3-amino-1,2,4-triazole (3-AT).

\section{EXPRESSION AND PURIFICATION OF FadR}

The cloning of $S$. oneidensis fabR and $f a d R$ for expression and purification has been described previously (Gao et al., 2008b). Soluble His-tagged FadR protein was expressed in $E$. coli BL21(DE3) induced with $0.3 \mathrm{mM}$ isopropyl $\beta$-D-1-thiogalactopyranoside (IPTG) at $30^{\circ} \mathrm{C}$ for $4 \mathrm{~h}$. Cells were collected by centrifugation, and resuspended in the lysis buffer (50 mM Tris/HCl, pH 7.5, $200 \mathrm{mM} \mathrm{NaCl,} 1 \mathrm{mM} \mathrm{MgCl}_{2}$, $10 \mathrm{mM} \beta$-mercaptoethanol, $1 \mathrm{mM}$ PMSF, $5 \mathrm{mg} / \mathrm{ml}$ DNase I), and subjected to thorough sonication. The soluble protein was purified using a nickel-ion affinity column according to Ni-NTA purification system manual (Invitrogen).

\section{ELECTROPHORETIC MOBILITY SHIFT ASSAY (EMSA)}

Biotin-labeled DNA probes were prepared by PCR from S. oneidensis genomic DNA with biotin-labeled primers and EMSA was carried out as described before (Gao et al., 2008a). Briefly, the binding reaction was performed with $\sim 2-5 \mathrm{nM}$ labeled probes and various amount of protein in $12 \mu \mathrm{l}$ binding buffer containing $100 \mathrm{mM}$ Tris/ $\mathrm{HCl}$ (pH 7.4), $20 \mathrm{mM} \mathrm{KCl,} 10 \mathrm{mM} \mathrm{MgCl}_{2}$, $2 \mathrm{mM}$ DTT, $0.2 \mu \mathrm{g} / \mu \mathrm{l}$ poly $(\mathrm{dI} \cdot \mathrm{dC})$, and $10 \%$ glycerol at $15^{\circ} \mathrm{C}$ for $60 \mathrm{~min}$. Reaction mixtures were immediately resolved on $6 \%$ polyacrylamide native gels, blotted onto nylon membranes, and cross-linked with a UV crosslinker. The imaging procedure followed Thermo Scientific's chemiluminescent nucleic acid detection module and was visualized with the UVP Imaging System.

\section{BIOINFORMATICS AND STATISTICAL ANALYSES}

Promoter prediction for genes of interest was performed by using promoter prediction program Neural Network Promoter Prediction (Reese, 2001). For statistical analysis, values are presented as means \pm SD (standard deviation). Student's-test was performed for pairwise comparisons of groups.

\section{RESULTS \\ S. ONEIDENSIS POSSESSES BOTH ANAEROBIC AND AEROBIC UFA BIOSYNTHESIS PATHWAYS}

According to the genome annotation, $S$. oneidensis has the $f a b A_{S o}$ (SO1856) (for differentiation, the same genes/proteins from multiple bacteria are labeled with abbreviated bacterial name in subscript) gene (Heidelberg et al., 2002), whose protein product shares up to $67 \%$ of sequence identity with FabA $\mathrm{Ec}_{\mathrm{c}}$ from E. coli. The gene is perfectly conserved in all sequenced Shewanella (data not shown), indicating that this group of bacteria own a typical anaerobic UFA synthesis pathway. However, genes encoding aerobic desaturases are not annotated. To assess whether $S$. oneidensis can also produce UFAs via an aerobic pathway, we screened the proteome with three well-studied desaturases essential to the process, Ole1p of $S$. cerevisiae, DesA of $P$. aeruginosa (DesA $A_{\mathrm{Pa}}$ ), and Des of B. subtilis (Stukey et al., 1990; Aguilar et al., 1998; Zhu et al., 2006). BLASTp returned the same single putative homolog against Ole1p and DesA $\mathrm{Pa}$, SO0197 (E-values $3 e-64$ and $2 e-11$, respectively). This protein shares sequence identity of $41 \%$ with the $\mathrm{N}$-terminal desaturase domain of Ole1p, which also carries a C-terminal domain that has strong homology to cytochromes $b_{5}$ (Mitchell and Martin, 1995). Like Olelp, 
SO0197 bears characteristics of membrane-bound desaturases, three trans-membrane domains and four histidine-rich clusters (Figure 1A). These features suggest that $S$. oneidensis may utilize SO0197 as an aerobic fatty acyl desaturase.

To confirm that FabAso and SO0197 function in the S. oneidensis UFA synthesis, in-frame deletion strains for their coding genes, individually and in combination, were constructed and assayed for growth under aerobic and anaerobic conditions. Both single knockout strains, $\triangle f a b A_{S o}$ and $\Delta S O 0197$, were obtained on LB plates. The $\triangle S O 0197$ strain was indistinguishable from the wild-type with respective to growth in liquid and solid media under aerobic and anaerobic conditions (Figures 1B,C). In contrast, the $\triangle f a b A_{S o}$ strain not only grew at a reduced rate under aerobic conditions but also required a UFA supplement, oleate of $0.005 \%$ (the same concentration was used through this study unless otherwise noted), for anaerobic growth. These growth defects were corrected when a copy of fab $A_{S o}$ was expressed in trans (Figure S1), confirming the essential role of FabA So $_{\text {in }}$ anaerobic UFAs biosynthesis. However, we failed to remove SO0197 in the absence of $f a b A_{S o}$ under routine conditions for mutagenesis. Given that the resolution step of the mutagenesis protocol theoretically gives the wild-type and mutant strains at 50:50 (Jin et al., 2013), the failure implicates a synthetical lethality under experimental conditions. We therefore reasoned that exogenous oleate may support growth of strains lacking both pathways. Indeed, when it was supplied, the $\Delta f a b A_{S o} \Delta S O 0197$ strain was obtained. Its dependence on exogenous oleate was confirmed by the observation that the double mutant could not grow without the addition (Figures 1B,C). Neither palmitate (C16:0) nor decanoate (C10:0) was able to rescue the synthetical lethal phenotype, suggesting that there unlikely exists an additional desaturase in S. oneidensis that can replace the function of missing enzymes (data not shown). When complemented by any of the deleted genes in trans, the $\Delta f a b A_{S o} \Delta S O 0197$ strain gained the ability to grow without exogenous oleate (Figure S1). These observations manifest that in the absence of FabAso SO0197 is a desaturase capable of generating sufficient UFAs to support growth. Given that the amino acid sequence similarity of SO0197 and DesA $\mathrm{Pa}_{\mathrm{Pa}}$ significantly higher than that of SO0197 and the other $P$. aeruginosa desaturase DesB $\mathrm{Pa}_{\mathrm{Pa}}$ (ClustalW2 score: 15.49 and 6.25, respectively), we named SO0197 as desAso. Unexpectedly, as shown in Figure 1D the double mutant strain lost the orange color, a signature feature of $S$. oneidensis because of abundant $c$-type cytochromes (Gao et al., 2010b; Jin et al., 2013), and the wild-type color was restored when either gene was expressed in trans. Given that the microorganism produces more than 40 such proteins (Meyer et al., 2004; Gao et al., 2010b; Fu et al., 2014b), this finding suggests that UFAs are crucial for cytochrome $c$ biosynthesis, which is currently under study.

It is worth mentioning that DesA $A_{P a}$ was not able to rescue the synthetical lethal phenotype resulting from losing both pathways when its coding gene was expressed under the control of the S. oneidensis arcA promoter, which is constitutively active (Gao et al., 2010a; Dong et al., 2012; Zhang et al., 2013; Sun et al., 2014) (Figure 1D). Thus, although both DesA proteins act as desaturases, they are not functionally exchangeable, presumably due to low sequence similarity. Moreover, $S$. oneidensis differs from $P$. aeruginosa in that the latter has

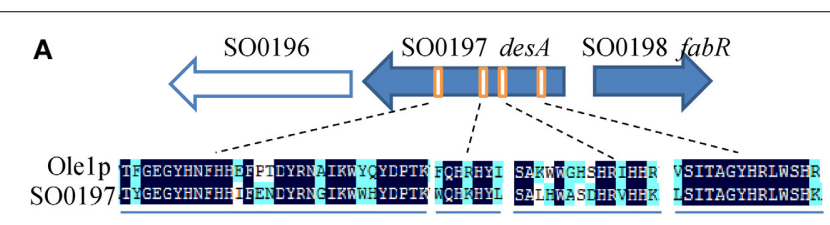

C

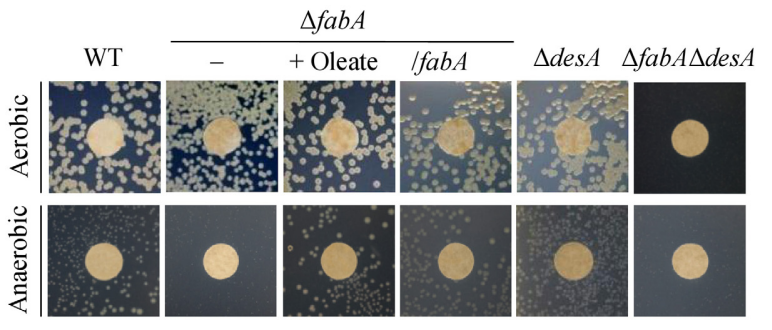

FIGURE 1 | $S$. oneidensis possesses both anaerobic and aerobic UFA biosynthesis pathways. (A) Genetic organization of desA $A_{S O}$ (SO0197) and comparison of the fatty acyl desaturase conserved histidine clusters, characteristic of desaturases. S. cerevisiae acyl-CoA desaturase (Ole1p) and DesA $_{S o}$ are aligned. Identical amino acids are highlighted in dark blue and similar amino acids are highlighted in light blue. (B) Growth of $\triangle \mathrm{fab} A_{S_{0}}$, $\Delta \operatorname{des} A_{\text {So, }}$, and $\Delta f a b A_{\text {So }} \Delta$ des $A_{\text {So }}$ strains in liquid media under aerobic and anaerobic conditions. Genetic complementation results are given in Figure S1. (C) Growth of $\Delta f a b A_{S o}, \Delta d e s A_{S o}$, and $\Delta f a b A_{S o} \Delta d e s A_{S o}$ strains on solid media. Cultures of the mid-log phase for each strain were properly diluted,

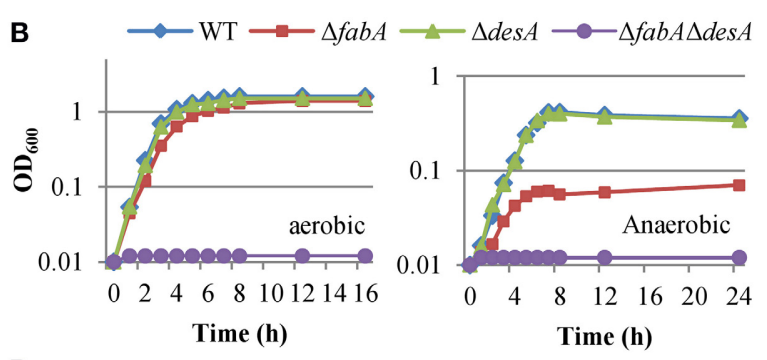

D

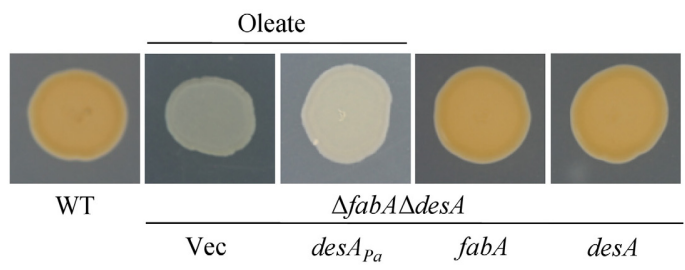

placed on LB plates, incubated for 24 and $48 \mathrm{~h}$ under aerobic and anaerobic conditions, respectively. $\triangle f_{a b} A_{S o}$ was complemented by chemically (supplement of oleate) or genetically (expression of fabA $A_{S o}$ in trans). (D) Colony color phenotype of mutants defective in UFA synthesis. In order to support growth of $\triangle \mathrm{fab} A_{S_{0}} \Delta d e s A_{S_{0}}$, oleate was supplemented when necessary. The double mutant was complemented by $\operatorname{des} A_{p_{a}}, f a b A_{S o}$, or des $A_{S o}$ in trans, with empty vector $(\mathrm{Vec})$ as control. $\triangle f_{a b A_{S o}}$ and $\Delta d e s A_{S o}$ strains were indistinguishable from WT (not shown). In (B-D) experiments were conducted independently at least three times and similar results were obtained (C,D) or standard deviations (less than $5 \%$ of the means) were omitted for clarity (B). 
an additional desaturase, $\operatorname{DesB}_{\mathrm{Pa}}$, which is proposed to selectively desaturates fatty acids from the environment (Zhu et al., 2006).

\section{S. ONEIDENSIS FadR AND FabR ARE INVOLVED IN REGULATION OF BOTH ANAEROBIC AND AEROBIC UFA SYNTHESIS PATHWAYS}

In $E$. coli, regulation of the anaerobic UFA biosynthesis pathway is carried out by $\mathrm{FadR}_{\mathrm{Ec}}$ and $\mathrm{FabR}_{\mathrm{Ec}}$ (Fujita et al., 2007), whose counterparts in $S$. oneidensis are apparent, FadR $\mathrm{So}_{\mathrm{SO}}$ (SO2885,

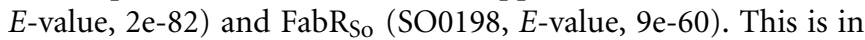
sharp contrast to $P$. aeruginosa, the only bacterium which has both anaerobic and aerobic UFA biosynthesis pathways and has been studied. A BLASTp search against the $P$. aeruginosa proteome using $F \mathrm{AdR}_{\mathrm{Ec}}$ returned many hits but none of them appeared to be a possible homolog (the smallest $E$-value, 2e-06). Moreover, the deletion of 25 of 27 GntR homologs did not significantly influence the bacterial response to exogenous fatty acids, suggesting that $P$. aeruginosa may not utilize a GntR family regulator for the role of FadR $\mathrm{Ec}_{\mathrm{c}}$ in E. coli (Choi and Schweizer, 2005). In P. aeruginosa, while little is known about how the $\operatorname{des} A_{P a}$ gene is regulated, the $\operatorname{des}_{\mathrm{Pa}}$ gene is under direct control of $\operatorname{Des}_{\mathrm{Pa}}$, a homolog of FabR $_{\text {Ec }}$ (Zhang et al., 2007). Consistently, a BLASTp search using $\operatorname{Des}_{\mathrm{Pa}}$ against $S$. oneidensis revealed a single putative homolog, FabR $_{\text {so }}\left(E\right.$-value, 1e-22). The $\operatorname{des}_{S o}$ and fabR $R_{S o}$ genes form a devergon (Figure 1A), a feature shared by the $\operatorname{des} B_{P a}$ and $\operatorname{des} T_{P a}$ genes, implicating a possibility that they may be physiologically associated.

To confirm the involvement of FadR So $_{\text {ond FabR }}$ an in UFA biosynthesis, mutants devoid of one of these genes were constructed. Under aerobic conditions, the $\Delta f a d R_{S o}$ strain grew significantly slower than the wild-type; its generation time ( $\sim 70 \mathrm{~min}$ ) was nearly doubled (Figure $2 \mathrm{~A})$ ). Similar results were obtained from anaerobic cultures, indicating that FadR $\mathrm{S}_{\mathrm{So}}$ influences both anaerobic and aerobic UFA biosynthesis pathways. The observed defect in growth was corrected by expressing the $f a d R_{S o}$ gene in trans under both conditions (Figure 2A), validating that the phenotype was due to the intended mutation. Importantly, the defect resulting from the $f a d R_{S o}$ deletion was also fully eliminated by adding oleate to the medium (Figure $2 B$ ), offering direct evidence that the $f a d R_{S o}$ mutation affects the synthesis of UFAs.
In contrast, the effect of deletion of the $f a b R_{S o}$ gene on growth under either aerobic or anaerobic conditions was insignificant. Moreover, the loss of either regulator did not significantly affect the colony color (data not shown). Overall, these data indicate that FadR $\mathrm{So}_{\mathrm{o}}$ has a more profound influence on UFA biosynthesis

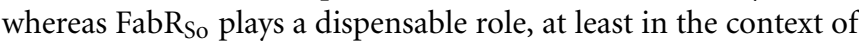
mutant phenotypes.

\section{LOSS OF FabA OR FadR SIGNIFICANTLY AFFECTS FATTY ACID COMPOSITION}

To gain an understanding of impacts of UFA biosynthesis pathways on fatty acids composition of $S$. oneidensis, the membranes of the wild-type, $\Delta f a b A_{S o}, \Delta d e s A_{S o}, \Delta f a b R_{S o}$, and $\Delta f a d R_{S o}$ strains were collected and assayed by GC-MS (Table 2). In the wild-type, SFAs, dominated by branched C15:0 (including both iso-C15:0 and antiiso-C15:0) and C16:0, accounted for $\sim 67 \%$ of the total membrane lipids whereas the remaining consisted of three UFAs, with C16:1 as the major. Loss of DesA $A_{\text {So }}$ had little impact on the composition, consistent with the accessory role that it plays in UFA biosynthesis. Similar results were obtained from the $\Delta f a b R_{S o}$ strain. Along with the observation that the loss of the $f a b R_{S o}$ gene does not elicit a distinguishable phenotype, these data indicate that the regulator is not a critical factor influencing the fatty acid composition of the S. oneidensis membrane. In contrast, removal of either $f a b A_{S o}$ or $f a d R_{S o}$ resulted in significantly altered fatty acid profiles. It was immediately evident that the percentages of iso-C15:0 and/or antiiso-C15:0 in both mutants increased substantially, especially in $\Delta f a d R_{S o}$ (up to $\sim 52 \%$ ). Additionally, levels of C14:0 were elevated up to 3-fold although its absolute abundance (up to 10\%) was low compared to branched C15:0. As a consequence, most of other fatty acids, such as C15:0, C16:1, C16:0, and C18:1, were present in reduced levels. The level of UFAs in the $\triangle f a b A$ strain was $\sim 77 \%$ relative to that in the wild-type, contrasting unaffected UFA biosynthesis in the absence of the desA gene. This observation further confirms that the anaerobic pathway dictates UFA biosynthesis. Moreover, the loss of FadR $\mathrm{So}_{\mathrm{o}}$ introduced a most drastic reduction in overall UFA levels, $\sim 48 \%$ relative to the wild-type level. These data conclude that FadR So $_{\text {in }}$ is crucial to UFA biosynthesis and its impact probably goes beyond the anaerobic pathway.

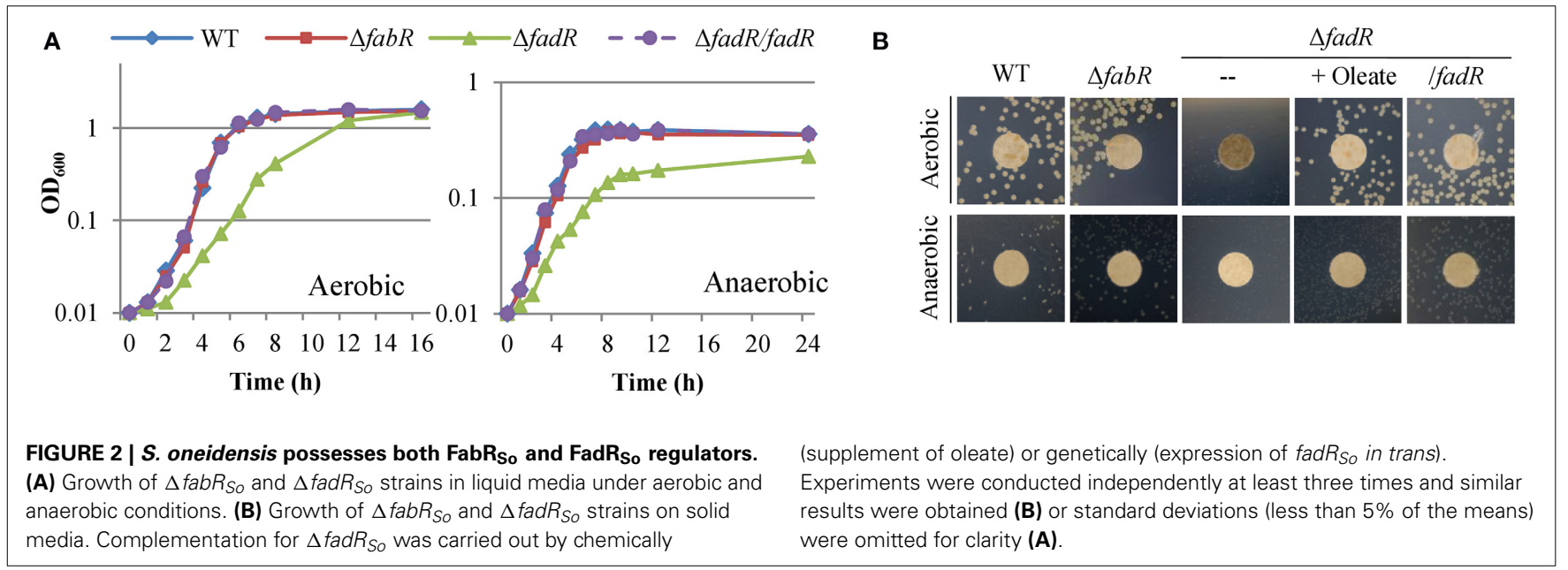


Table 2 | Fatty acid composition of $\boldsymbol{S}$. oneidensis strains.

\begin{tabular}{|c|c|c|c|c|c|c|c|c|}
\hline Strain & C14:1 & C14:0 & i-C15:0 & C15:0 & C16:1 & C16:0 & C18:1 & C18:0 \\
\hline$\triangle f a b A$ & $1.85 \pm 0.94$ & $7.55 \pm 0.16$ & $34.06 \pm 9.54$ & $5.05 \pm 0.94$ & $21.58 \pm 3.75$ & $22.11 \pm 4.54$ & $2.06 \pm 0.16$ & $5.74 \pm 0.31$ \\
\hline$\Delta f a b R$ & $3.01 \pm 1.45$ & $2.62 \pm 0.81$ & $21.68 \pm 8.41$ & $2.51 \pm 0.65$ & $30.55 \pm 8.73$ & $27.51 \pm 7.44$ & $6.11 \pm 3.39$ & $6.01 \pm 2.10$ \\
\hline$\Delta f a d R$ & $4.14 \pm 0.29$ & $9.77 \pm 1.59$ & $52.71 \pm 13.7$ & $0.71 \pm 0.04$ & $10.65 \pm 1.30$ & $15.31 \pm 4.76$ & $1.46 \pm 0.43$ & $5.25 \pm 1.59$ \\
\hline$\Delta f a b A \Delta d e s A^{a}$ & $2.55 \pm 0.82$ & $4.81 \pm 0.96$ & $19.69 \pm 8.65$ & $0.67 \pm 0.14$ & $14.43 \pm 1.51$ & $26.73 \pm 2.61$ & $25.83 \pm 3.4$ & $5.29 \pm 0.92$ \\
\hline
\end{tabular}

${ }^{a} 0.005 \%$ oleate supplemented in culture.

\section{THE ABSENCE OF THE ANAEROBIC PATHWAY INDUCES AN ENHANCED TRANSCRIPTION OF THE desA GENE}

Results presented thus far indicate that the anaerobic pathway is critical to UFA biosynthesis in S. oneidensis. However, cells retain ability to produce a considerable amount of UFAs in its absence, implicating a possibility that the aerobic pathway enlarges its role when the anaerobic pathway is gone. To test this, a lac $Z$ reporter system was employed to assess the activities of the $f a b A_{S o}$ and $\operatorname{des}_{S o}$ promoters in the wild-type, $\Delta f a b A_{S o}$, and $\Delta d e s A_{S o}$ strains (Fu et al., 2014a). For both genes, the most confident promoters, predicted by using Neural Network Promoter Prediction (NNPP) (Reese, 2001), are within 100 bp upstream of their coding sequence. Proper reporter vectors were constructed by placing fragments of $\sim 300 \mathrm{bp}$ covering the predicted promoters in front of the full length $E$. coli lac $Z$ gene and introduced into the relevant strains. After chromosome integration and the antibiotic marker removal, activities of these two promoters in a single copy were assayed (Figure 3). When grown under aerobic conditions, the activity of the $f a b A_{S o}$ promoter in the $\Delta d e s A_{S o}$ strain increased slightly, compared to that in the wild-type. In contrast, deletion of the $f a b A_{S o}$ gene caused an elevation of $\sim 3.5$-fold for the $\operatorname{des} A_{S o}$ promoter activity. Similar observations were obtained by using qRT-PCR (data not shown), indicating a complement role of the aerobic pathway for UFA production when the anaerobic pathway is absent.

We then evaluated influences of oleate (UFA) and palmitate (SFA) on these two UFA biosynthesis pathways. Activities of the $\operatorname{des} A_{S o}$ and $f a b A_{S o}$ promoters were assayed in cells grown with addition of either the fatty acid (Figure 3 ). In the wild-type background, exogenous oleate reduced $f a b A_{S o}$ promoter activity to approximately a half but showed a modest impact on expression of the des $A_{S o}$ gene. Similar effects were observed from the $f a b A_{S o}$, and $\operatorname{des} A_{\text {So }}$ mutant strains. Notably, the induction of the $\operatorname{des} A_{S o}$ gene upon removal of FabAso was no longer evident. On the contrary, the SFA addition induced both genes substantially, largely independent of $\mathrm{FabA}_{\text {So }}$ or DesA $\mathrm{S}_{\mathrm{So}}$. These results manifest that the supplement of UFAs suppresses expression of both UFA synthesis pathways whereas SFAs confer an opposite effect.

\section{DIRECT ROLES OF FadR SO AND FabR SO IN REGULATION OF UFA SYNTHESIS PATHWAYS}

In E. coli, both FadR $\mathrm{Ec}_{\mathrm{c}}$ and $\mathrm{FabR}_{\mathrm{Ec}}$ directly regulate the $f a b A_{E c}$ gene whereas $P$. aeruginosa Des $\mathrm{T}_{\mathrm{Pa}}$ represses expression of des $B$ (Zhang et al., 2002, 2007; Zhu et al., 2009). To assess effects of FabR So $_{\text {and }}$ aadR $\mathrm{So}_{\text {So }}$ on expression of the fabA $A_{S o}$ and $\operatorname{des} A_{S o}$

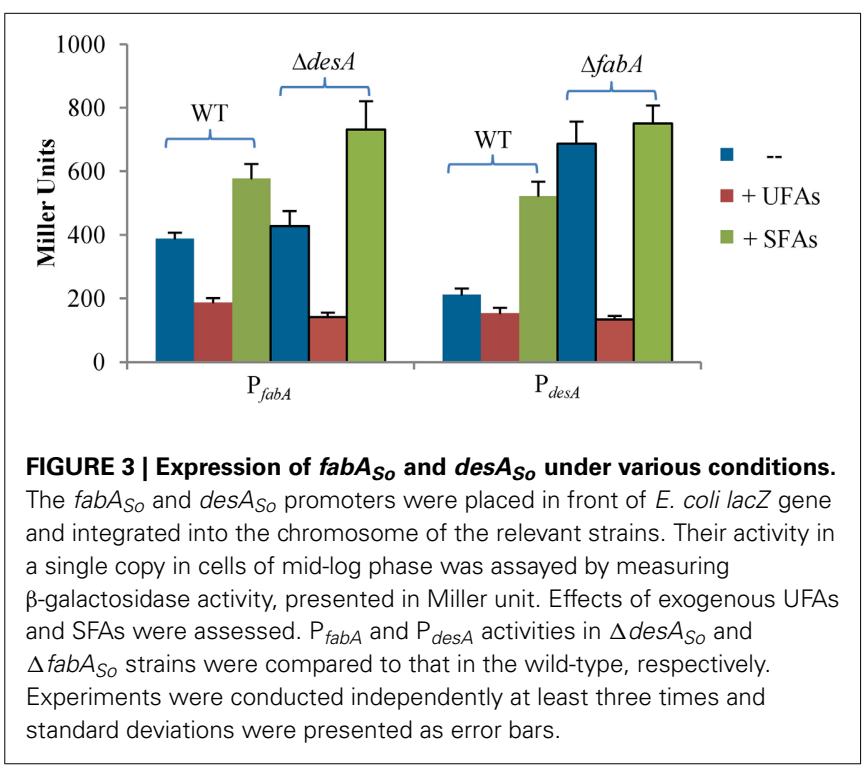

genes in vivo, we measured the activities of the fab $A_{S o}$ and $\operatorname{des} A_{S o}$ promoters using the lac $Z$-reporters described above (Figure 4). In the absence of FabR $\mathrm{S}_{\mathrm{So}}, \beta$-galactosidase activities driven by the $f a b A_{S o}$ and $\operatorname{des} A_{S o}$ promoters increased $\sim 2$ - and 5-fold, respectively, suggesting that the regulator functions as a repressor for

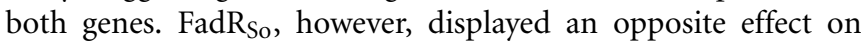
expression of the $f a b A_{S o}$ and des $A_{\text {So }}$ genes, at respective $\sim 40 \%$ and $\sim 5$-fold relative to the wild type levels in its absence. This observation suggests that FadR $_{\text {So }}$ acts as an activator for the anaerobic pathway and a repressor for the aerobic pathway. Additionally, we examined whether FabR $\mathrm{R}_{\text {so }}$ autoregulates its own expression given that its coding gene shares the intergenic region with the $\operatorname{des} A_{S o}$ gene. A fragment of $\sim 300 \mathrm{bp}$ upstream of the $f a b R_{S o}$ gene, covering the intergenic region separating these two genes (144 bp), was amplified and placed in front of the E. coli lac $Z$ gene to construct the $\mathrm{P}_{f a b R}$-lac $Z$ reporter. By using this system, we found that the $f a b R_{\text {So }}$ promoter activity seemed constitutive, hardly affected by loss of either FabR $\mathrm{So}_{\mathrm{o}}$ or FadR $\mathrm{So}_{\mathrm{O}}$ (Figure 4).

\section{FadR $_{\text {SO }}$ DIRECTLY CONTROLS FabA so $_{\text {BUT NOT DesA }}$}

As shown above, loss of FadR So $_{\text {or }}$ FabR So $_{\text {o }}$ results in significantly altered expression of the $f a b A_{S o}$ and $\operatorname{des} A_{S o}$ genes. According to the prediction made by NNPP, the most confident $\operatorname{des} A_{S o}$ promoter starts at the "A" of -42 relative to the translation initiation code ATG. To confirm this, a series of fragments varying in 
length were amplified and placed before the E. coli lacZ gene for the promoter activity assay (Figure 5A). In the background of the wild-type, the fragments of $\mathrm{P}_{1}$ (up to $-100 \mathrm{bp}$ ) and $\mathrm{P}_{2}$ (up to $-71 \mathrm{bp}$ ) were able to drive the $\beta$-galactosidase production at levels comparable to that with the fragment of $\sim 300 \mathrm{bp}$ as shown in Figures 3, 4, 5B, indicating that the promoter is included in both $\mathrm{P}_{1}$ and $\mathrm{P}_{2}$. In contrast, the activities of the $\beta$-galactosidase were not detected with $\mathrm{P}_{3}$ (up to $-42 \mathrm{bp}$ ) or $\mathrm{P}_{4}$ (up to $-24 \mathrm{bp}$ ), indicating that these fragments do not cover the intact promoter. Moreover, all fragments tested behaved as expected in the $f a d R_{S o}$ and $f a b R_{S o}$ deletion strains (Figures 4, 5B). These data support that the promoter lies between -71 and -42 , in perfect agreement with the prediction. It is worth noting that the sequence of $18 \mathrm{bp}$ starting with the predicted transcriptional starting nucleotide "A" closely resembles the FabR $_{\mathrm{Ec}}$-binding motif (-AGCGTACACGTGTTCGCT-, the same nucleotides are underlined) (Feng and Cronan, 2011), implying that the $\operatorname{des} A_{S o}$ gene is under direct repression of FabR So $_{\text {. }}$

Although, expression of the $\operatorname{des} A_{\text {So }}$ gene is substantially upreg-

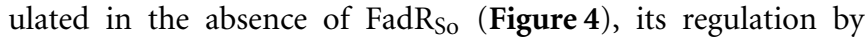

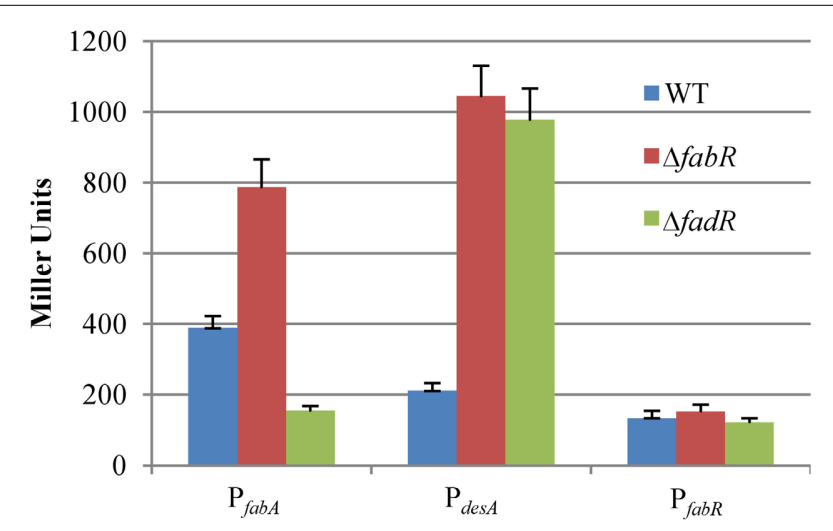

FIGURE 4 | Effects of FabR So $_{\text {and FadR }}$ so on expression of fab $A_{\text {So, }}$

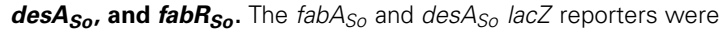
described in Figure $\mathbf{3}$ and the fab $R_{\text {So }}$ lac $Z$ reporter was similarly constructed. Experiments were conducted independently at least three times and standard deviations were presented as error bars.
FadR may be indirect as the increased $\operatorname{des} A_{S o}$ expression may be a result of the reduced production of FabA, a phenomenon shown in Figure 3. To test whether FadR So $_{\text {ond/or FabR }}$ interacts with DNA fragments upstream of the $f a b A_{S o}$ and desA $A_{S o}$ genes, we employed a DNA-binding gel shift assay. Both FadR $\mathrm{So}_{\mathrm{S}}$ and FabR $\mathrm{So}_{\text {o }}$ with the N-terminal His-tag were subjected to expression and purification from E. coli. Soluble FadR So $_{\text {o }}$ was obtained smoothly (Figure 6A). In contrast, we were unable to purify FabR $_{\text {So }}$ after many attempts, a scenario reported before with E. coli and Vibrio cholerae FabR, implicating that the same frustrating properties are shared by these proteins (Feng and Cronan, 2011). The DNA fragments, $\sim 300$ bp in length centered by the predicted promoter of the genes to be tested, were prepared by

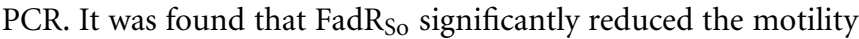
of the fragments for $f a b A_{S o}$ at a protein concentration of $0.5 \mu \mathrm{M}$. The strongest binding was observed with the protein at $2 \mu \mathrm{M}$. The specific binding was validated by that the binding was completely blocked by excessive $(50 \mathrm{x})$ unlabeled the same probe but not blocked by non-specific competitor of $2 \mu \mathrm{g} / \mu \mathrm{l}$ poly $\mathrm{dI} \cdot \mathrm{dC}$. In contrast, no interaction was found with the $\operatorname{des} A_{\text {So }}$ promoter

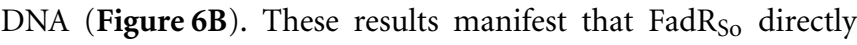
controls $f a b A_{S o}$ but not $\operatorname{des} A_{S o}$ although expression of both genes is significantly altered in its absence.

\section{FabR DIRECTLY REPRESSES BOTH fabA AND $\operatorname{desA}$}

Given our inability to obtain soluble $\mathrm{FabR}_{\text {So }}$, we turned to Bacterial one-hybrid $(\mathrm{B} 1 \mathrm{H})$ system to investigate DNA-protein interaction in vivo in E. coli cells (Guo et al., 2009). Positive interaction between "bait" (DNA) and "target" (DNA-binding regulator) allows the reporter strain to grow on 3-amino-1,2,4triazole (3-AT). To prepare the bait, a $\sim 300 \mathrm{bp}$ fragment of $f a b A_{S o}$ or $\operatorname{des} A_{\text {So }}$ centered by the predicted binding sequence or the promoter sequence was cloned into $\mathrm{pBXcmT}$, which was paired with pTRG carrying either the $f a b R_{S o}$ gene or the $f a d R_{S o}$ gene for co-transformation. The system was validated with positive control pairs $\left(\mathrm{P}_{k a t B} / \mathrm{OxyR}\right.$ of $S$. oneidensis $)$ and negative control plasmid pair $\left(\mathrm{P}_{165} / \mathrm{OxyR}\right.$ of $S$. oneidensis), which showed strong and no interaction in our previous work, respectively (Jiang et al., 2014; Li et al., 2014) (Table 3). While positive interactions from $\mathrm{P}_{\text {fabASo }} / \mathrm{FadR}_{\text {So }}$ were detected and confirmed by growth

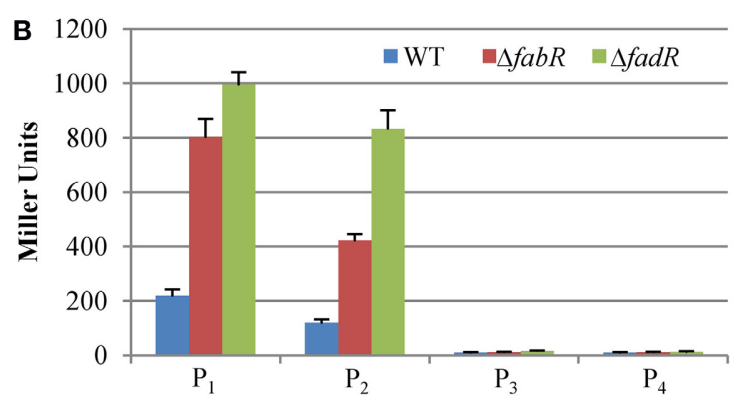

comparison). (B) Activities of four constructs in (A) in WT, $\Delta$ des $A_{\text {So }}$ and $\triangle f_{a b} A_{S o}$ strains. Experiments were conducted independently at least three times and standard deviations were presented as error bars. 

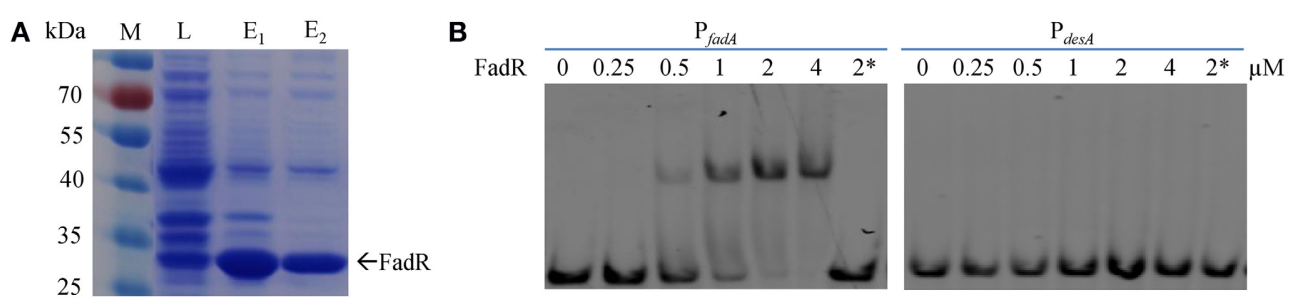

FIGURE 6 | FadRso-binding to selected promoters by EMSA. (A)

Overproduced and purified recombinant $S$. oneidensis $\mathrm{His}_{6}-\mathrm{FadR}_{\mathrm{So}}$ from E. coli BL21 cells. M, protein marker; L, lysates; $E_{1}$, elute from the first round purification; $E_{2}$, elute from the second round purification; $(\mathbf{B})$ Interaction of $\mathrm{P}_{\text {fadA }}$ and $\mathrm{P}_{\text {desA }}$ DNAs with $\mathrm{His}_{6}-\mathrm{FadR}_{\mathrm{So}}$. The probes were prepared by PCR with end-labeled primers. EMSA was performed with $2 \mathrm{nM}$ end-labeled probes and various amounts of proteins. Non-specific competitor DNA $(2 \mu \mathrm{g} / \mu \mathrm{l}$ poly $\mathrm{dl} \cdot \mathrm{dC})$ was added to the lane with $2 \mu \mathrm{M}$ protein and specific competitor (100 nM unlabeled $\mathrm{P}_{\text {fadA }}$ and $\mathrm{P}_{\text {des }}$ probes) was added to the lane with $2 \mu \mathrm{M}$ protein marked by an asterisk.
Table 3 | Bacterial one-hybrid (B1H) assay of FabR So $_{\text {and }}$ adR So $_{\text {o }}$ with various $S$. oneidensis promoters.

\begin{tabular}{|c|c|c|c|c|c|}
\hline $\begin{array}{l}\text { Bait } \\
\text { vector } \\
\text { pBXcmT }\end{array}$ & $\begin{array}{l}\text { Target } \\
\text { vector } \\
\text { pTRG }\end{array}$ & $\begin{array}{l}\text { Colonies on } \\
\text { NS plates }\end{array}$ & $\begin{array}{c}\text { Colonies on } \\
\text { S plates }^{b}\end{array}$ & C plates ${ }^{c}$ & Interaction \\
\hline 1- & $1-$ & 207 & 0 & - & No \\
\hline 1- & $\operatorname{lOxyR}_{\text {So }}$ & 183 & 0 & - & No \\
\hline$/ P_{\text {katB }}$ & /OxyR $_{\text {So }}$ & 179 & 165 & 164 & $\begin{array}{l}\text { Yes (Positive } \\
\text { control) }\end{array}$ \\
\hline$/ P_{\text {katB }}$ & $1-$ & 213 & 0 & - & No \\
\hline$/ P_{16 S}$ & IOxyR $_{\text {So }}$ & 162 & 0 & - & $\begin{array}{l}\text { No (negative } \\
\text { control) }\end{array}$ \\
\hline$/ P_{16 S}$ & $/$ FabR $_{\text {So }}$ & 203 & 2 & 0 & $\begin{array}{l}\text { No (negative } \\
\text { control) }\end{array}$ \\
\hline$/ P_{f a b A}$ & /FabR ${ }_{\text {So }}$ & 158 & 154 & 153 & Yes \\
\hline$/ P_{\text {des } A}$ & /FabRso & 212 & 201 & 199 & Yes \\
\hline$/ P_{16 S}$ & /FadRso & 177 & 0 & 0 & $\begin{array}{l}\text { No (negative } \\
\text { control) }\end{array}$ \\
\hline$/ P_{f a b A}$ & $/$ FadR $_{\text {So }}$ & 173 & 182 & 182 & Yes \\
\hline$/ P_{\text {des } A}$ & /FadR $_{\text {So }}$ & 193 & 1 & 0 & Yes \\
\hline
\end{tabular}

${ }^{a} N S$ plates, non-selective plates: $M 9$ agar $+25 \mu \mathrm{g} / \mathrm{ml}$ chloramphenicol + $12.5 \mu \mathrm{g} / \mathrm{m} /$ tetracycline.

${ }^{b} S$ plates, selective plates: $a+5 m M 3-A T$.

${ }^{c} C$ plates, confirmation plates: $b+12.5 \mu \mathrm{g} / \mathrm{m} /$ streptomycin.

on plates containing both 3 -AT and streptomycin $(12.5 \mathrm{mg} / \mathrm{ml})$, no colonies were obtained from $\mathrm{P}_{d e s A S o} / \mathrm{FadR}_{\mathrm{So}}$, supporting the EMSA result. With FabR $\mathrm{R}_{\text {so }}$ as the target, both $\mathrm{P}_{\text {fabASo }}$ and $\mathrm{P}_{\text {desASo }}$ generated positive results, suggesting that FabR $\mathrm{So}_{\text {o }}$ likely interact with the intergenic sequence of both the $f a b A_{S o}$ and $d e s A_{S o}$ genes.

\section{DISCUSSION}

Bacteria often reside in the environment with constantly changing parameters, such as temperature, organic-solvent concentration, and $\mathrm{pH}$, that require the immediate modification of existing membrane phospholipid acyl chains to optimize fitness under the new conditions. To control the production of a variety of fatty acids with different melting temperatures to achieve the proper physical state of the membrane phospholipids, the SFA, UFA, and BCFA biosynthesis pathways must be strictly regulated according to the availability of fatty acids (Zhang and Rock, 2008).
In the present study, we show that facultative Gram-negative $\gamma$ proteobacterium S. oneidensis possesses both aerobic and anaerobic UFA synthesis pathways, a scenario reported before only in $P$. aeruginosa (Zhu et al., 2006). Both bacteria own a FabAbased anaerobic UFA synthesis pathway, which resembles the well-studied one from $E$. coli. In the case of the aerobic UFA synthesis pathway, however, significant differences are found. Unlike $P$. aeruginosa, which is equipped with two desaturases DesA and DesB, S. oneidensis contains only one. Based on the sequence similarity, the $S$. oneidensis desaturase is likely a counterpart of $P$. aeruginosa DesA. Moreover, DesA proteins in both bacteria appear to be sufficient for the desaturation reaction whereas $P$. aeruginosa DesB is predicted to be functionally associated with DesC, whose coding gene forms an operon with des $B$. However, with respect to synteny, the $S$. oneidensis $\operatorname{des} A$ is more closely related to the $P$. aeruginosa des $B$, both of which form a divergent with their repressive regulators, FabR and DesT, respectively (Zhu et al., 2006; Zhang et al., 2007). Given that FadR has not been identified in P. aeruginosa, S. oneidensis is a good research model for studying regulation of UFA biosynthesis in bacteria owning both aerobic and anaerobic UFA synthesis pathways.

In line with $P$. aeruginosa, the anaerobic pathway undoubtedly plays a dominant role in UFA biosynthesis as the loss of DesA barely affects the fatty acid composition whereas the profound changes result from the removal of FabA in S. oneidensis (Zhu et al., 2006). The major UFA found in S. oneidensis membrane is C16:1, consistent with previous reports (Venkateswaran et al., 1999; Abboud et al., 2005). Although bacteria commonly produce more UFAs as a means to increase membrane fluidity, it is not adopted by $S$. oneidensis as a major strategy. Instead, the enhanced fluidity is achieved by elevating the proportion of BCFAs (mainly iso- and antiiso-C15:0), from $\sim 25 \%$ at $22{ }^{\circ} \mathrm{C}$ to $\sim 74 \%$ at $3^{\circ} \mathrm{C}$ (Abboud et al., 2005). In the present study, we found that production of BCFAs is increased in reverse proportional to production of UFAs, supporting the predominant role of BCFAs in determining membrane fluidity. Consistent with the dominant role of the anaerobic pathway in UFA biosynthesis, this phenomenon was observed only when anaerobic rather than aerobic pathway is damaged, as in strains lacking either FabA or FadR.

Despite subordinate, the aerobic pathway is important in the absence of the anaerobic pathway. In addition to their role in maintaining membrane structure and function, UFAs are 
involved in many biological processes, some of which may yet be properly appreciated. For example, for the first time we showed here that cytochrome $c$ biosynthesis is dependent on UFAs. As S. oneidensis produces more than 40 such proteins, which are largely responsible for its respiratory versatility (Meyer et al., 2004; Gao et al., 2010b; Jin et al., 2013; Fu et al., 2014b), such a finding implies that UFAs are critical for features that are currently exploited for application.

To be more effective in complementing to the anaerobic pathway, expression of the $\operatorname{des} A$ gene is substantially increased when FabA is depleted. Although we do not yet know how this is achieved, the underlying mechanism may also account for enhanced expression of $\operatorname{des} A$ in the absence of FadR. Our data obtained from both in vivo and in vitro analyses demonstrated that FadR directly activates transcription of the fabA gene but affects expression of $\operatorname{des} A$ in an indirect manner. Thus, increased expression of $\operatorname{des} A$ in the strain lacking FadR is probably a result of decreased production of FabA. FabR acts as a repressor for the $\operatorname{des} A$ gene, similar to DesT for $\operatorname{des} B$ in $P$. aeruginosa (Zhu et al., 2006; Zhang et al., 2007; Miller et al., 2010). Given that both DesT $_{\mathrm{Pa}}$ and FabR $\mathrm{So}_{\mathrm{s}}$ are homologs of E. coli FabR $\mathrm{Ec}$, it is possible that these two proteins are functional counterparts. Both FabR $_{E c}$ and Des $T_{P a}$ were proposed to respond to the composition of fatty acids (the UFA:SFA ratio of the acyl-ACP pool) available for membrane phospholipid synthesis to adjust expression of relevant genes for properly balanced production of UFA and SFA (Zhu et al., 2009; Miller et al., 2010). However, this notion was challenged later, at least in the case of $\mathrm{FabR}_{\mathrm{Ec}}$, by the finding that $F_{a b R_{E c}}$ primarily functions to report the presence of exogenous UFA (as their CoA esters) rather than the composition (Feng and Cronan, 2011). Our data manifested that no matter what FabR $_{\text {So }}$ and DesT $_{\mathrm{Pa}}$ respond to, their regulatory effect is modest.

Unlike E. coli, which has the anaerobic pathway only, S. oneidensis and $P$. aeruginosa possess two pathways and the dominant role of the anaerobic pathway in UFA synthesis overwhelms the contribution of the aerobic pathway (Campbell and Cronan, 2001; Zhu et al., 2006). The minor effect of losing DesT $T_{P a}$ can be readily explained because this regulator does not influence expression of the $f a b A_{P a}$ gene of the anaerobic pathway ( $\mathrm{Zhu}$ et al., 2006). However, this is not the case in S. oneidensis. FabR So $_{\text {acts }}$ as a repressor for both the $f a b A_{S o}$ and $\operatorname{des} A_{S o}$ genes. Although the expression of $f a b A_{S o}$ is elevated by $\sim 2$-fold in the $\Delta f a b R_{S o}$ strain, the fatty acid composition is not noticeably altered, indicating that FabA produced at the wild-type level is sufficient to maintain balanced membrane lipid homeostasis. In the absence of $\mathrm{FadR}_{\mathrm{So}}$, in contrast, the expression of $f a b A_{S o}$ is too low to ensure UFA production. Combining the finding that the strain lacking FadR $_{\text {So }}$ overall suffers more severe impairment than that missing FabAso $_{\text {So }}$, we speculate that the regulatory scope of FadR $\mathrm{So}_{\text {o }}$ is not limited to fatty acid biosynthesis. Efforts to define the regulon of FadR $_{\text {So }}$ are underway.

\section{ACKNOWLEDGMENTS}

This research was supported by National Natural Science Foundation of China (31270097, 41476105), Major State Basic Research Development Program (973 Program: 2010CB833803), and Doctoral Fund of Ministry of Education of China (20130101110142).

\section{SUPPLEMENTARY MATERIAL}

The Supplementary Material for this article can be found online at: http://www.frontiersin.org/journal/10.3389/fmicb. 2014.00736/abstract

\section{REFERENCES}

Abboud, R., Popa, R., Souza-Egipsy, V., Giometti, C. S., Tollaksen, S., Mosher, J. J., et al. (2005). Low-temperature growth of Shewanella oneidensis MR-1. Appl. Environ. Microbiol. 71, 811-816. doi: 10.1128/AEM.71.2.811-816.2005

Aguilar, P. S., Cronan, J. E., and de Mendoza, D. (1998). A Bacillus subtilis gene induced by cold shock encodes a membrane phospholipid desaturase. J. Bacteriol. 180, 2194-2200.

Altabe, S., Mansilla, M., and de Mendoza, D. (2013). "Remodeling of membrane phospholipids by bacterial desaturases," in Stearoyl-CoA Desaturase Genes in Lipid Metabolism, ed P. D. J. M. Ntambi (New York, NY: Springer), 209-231.

Auawithoothij, W., and Noomhorm, A. (2012). Shewanella putrefaciens, a major microbial species related to tetrodotoxin (TTX)-accumulation of puffer fish Lagocephalus lunaris. J. Appl. Microbiol. 113, 459-465. doi: 10.1111/j.13652672.2012.05339.x

Bligh, E. G., and Dyer, W. J. (1959). A rapid method of total lipid extraction and purification. Can. J. Biochem. Physiol. 37, 911-917. doi: 10.1139/o59-099

Campbell, J. W., and Cronan, J. E. (2001). bacterial fatty acid biosynthesis: targets for antibacterial drug discovery. Annu. Rev. Microbiol. 55, 305-332. doi: 10.1146/annurev.micro.55.1.305

Choi, K.-H., and Schweizer, H. (2005). An improved method for rapid generation of unmarked Pseudomonas aeruginosa deletion mutants. BMC Microbiol. 5:30. doi: 10.1186/1471-2180-5-30

Cronan, J. E. (2006). A bacterium that has three pathways to regulate membrane lipid fluidity. Mol. Microbiol. 60, 256-259. doi: 10.1111/j.13652958.2006.05107.x

Cronan, J. E., Birge, C. H., and Vagelos, P. R. (1969). Evidence for two genes specifically involved in unsaturated fatty acid biosynthesis in Escherichia coli. J. Bacteriol. 100, 601-604.

Cronan, J. J. E., and Subrahmanyam, S. (1998). FadR, transcriptional co-ordination of metabolic expediency. Mol. Microbiol. 29, 937-943. doi: 10.1046/j.13652958.1998.00917.x

Cybulski, L. E., Martín, M., Mansilla, M. C., Fernández, A., and de Mendoza, D. (2010). Membrane thickness cue for cold sensing in a bacterium. Curr. Biol. 20, 1539-1544. doi: 10.1016/j.cub.2010.06.074

Dong, Y., Wang, J., Fu, H., Zhou, G., Shi, M., and Gao, H. (2012). A Crp-dependent two-component system regulates nitrate and nitrite respiration in Shewanella oneidensis. PLoS ONE 7:e51643. doi: 10.1371/journal.pone.0051643

Feng, Y., and Cronan, J. E. (2011). Complex binding of the FabR repressor of bacterial unsaturated fatty acid biosynthesis to its cognate promoters. Mol. Microbiol. 80, 195-218. doi: 10.1111/j.1365-2958.2011.07564.x

Fredrickson, J. K., Romine, M. F., Beliaev, A. S., Auchtung, J. M., Driscoll, M. E., Gardner, T. S., et al. (2008). Towards environmental systems biology of Shewanella. Nat. Rev. Micro. 6, 592-603. doi: 10.1038/nrmicro1947

Fu, H., Chen, H., Wang, J., Zhou, G., Zhang, H., Zhang, L., et al. (2013). Crpdependent cytochrome bd oxidase confers nitrite resistance to Shewanella oneidensis. Environ. Microbiol. 15, 2198-2212. doi: 10.1111/1462-2920.12091

Fu, H., Jin, M., Ju, L., Mao, Y., and Gao, H. (2014a). Evidence for function overlapping of CymA and the cytochrome $b c_{1}$ complex in the Shewanella oneidensis nitrate and nitrite respiration. Environ. Microbiol. 16, 3181-3195. doi: $10.1111 / 1462-2920.12457$

Fu, H., Jin, M., Wan, F., and Gao, H. (2014b). Shewanella oneidensis cytochrome $c$ maturation component $\mathrm{CcmI}$ is essential for heme attachment at the non-canonical motif of nitrite reductase NrfA. Mol. Microbiol. doi: 10.1111/mmi.12865. [Epub ahead of print].

Fujita, Y., Matsuoka, H., and Hirooka, K. (2007). Regulation of fatty acid metabolism in bacteria. Mol. Microbiol. 66, 829-839. doi: 10.1111/j.13652958.2007.05947.x

Gao, H., Barua, S., Liang, Y., Wu, L., Dong, Y., Reed, S., et al. (2010b). Impacts of Shewanella oneidensis $c$-type cytochromes on aerobic and anaerobic respiration. Microb. Biotechnol. 3, 455-466. doi: 10.1111/j.1751-7915.2010.00181.x 
Gao, H., Pattison, D., Yan, T., Klingeman, D. M., Wang, X., Petrosino, J., et al. (2008b). Generation and validation of a Shewanella oneidensis MR-1 clone set for protein expression and phage display. PLoS ONE 3:e2983. doi: 10.1371/journal.pone.0002983

Gao, H., Wang, X., Yang, Z., Palzkill, T., and Zhou, J. (2008a). Probing regulon of ArcA in Shewanella oneidensis MR-1 by integrated genomic analyses. BMC Genomics 9:42. doi: 10.1186/1471-2164-9-42

Gao, H., Wang, X., Yang, Z. K., Chen, J., Liang, Y., Chen, H., et al. (2010a). Physiological roles of ArcA, Crp, and EtrA and their interactive control on aerobic and anaerobic respiration in Shewanella oneidensis. PLoS ONE 5:e15295. doi: 10.1371/journal.pone.0015295

Guo, M., Feng, H., Zhang, J., Wang, W., Wang, Y., Li, Y., et al. (2009). Dissecting transcription regulatory pathways through a new bacterial one-hybrid reporter system. Genome Res. 19, 1301-1308. doi: 10.1101/gr.086595.108

Heidelberg, J. F., Paulsen, I. T., Nelson, K. E., Gaidos, E. J., Nelson, W. C., Read, T. D., et al. (2002). Genome sequence of the dissimilatory metal ionreducing bacterium Shewanella oneidensis. Nat. Biotechnol. 20, 1118-1123. doi: $10.1038 /$ nbt749

Henry, M. F., and Cronan, J. E. Jr. (1992). A new mechanism of transcriptional regulation: release of an activator triggered by small molecule binding. Cell 70, 671-679. doi: 10.1016/0092-8674(92)90435-F

Janda, J. M., and Abbott, S. L. (2014). The genus Shewanella: from the briny depths below to human pathogen. Crit. Rev. Microbiol. 40, 293-312. doi: 10.3109/1040841X.2012.726209

Jiang, Y., Dong, Y., Luo, Q., Li, N., Wu, G., and Gao, H. (2014). Protection from oxidative stress relies mainly on derepression of OxyR-dependent KatB and Dps in Shewanella oneidensis. J. Bacteriol. 196, 445-458. doi: 10.1128/JB.01077-13

Jin, M., Jiang, Y., Sun, L., Yin, J., Fu, H., Wu, G., et al. (2013). Unique organizational and functional features of the cytochrome $c$ maturation system in Shewanella oneidensis. PLoS ONE 8:e75610. doi: 10.1371/journal.pone.0075610

Li, N., Luo, Q., Jiang, Y., Wu, G., and Gao, H. (2014). Managing oxidative stresses in Shewanella oneidensis: intertwined roles of the OxyR and OhrR regulons. Environ. Microbiol. 16, 1821-1834. doi: 10.1111/1462-2920.12418

Marrakchi, H., Choi, K.-H., and Rock, C. O. (2002). A new mechanism for anaerobic unsaturated fatty acid formation in Streptococcus pneumoniae. J. Biol Chem. 277, 44809-44816. doi: 10.1074/jbc.M208920200

McCue, L. A., Thompson, W., Carmack, C. S., Ryan, M. P., Liu, J. S., Derbyshire, V., et al. (2001). Phylogenetic footprinting of transcription factor binding sites in proteobacterial genomes. Nucleic Acids Res. 29, 774-782. doi: $10.1093 /$ nar/29.3.774

Mendoza, D. D. (2014). Temperature sensing by membranes. Annu. Rev. Microbiol. 68, 101-116. doi: 10.1146/annurev-micro-091313-103612

Meyer, T. E., Tsapin, A. I., Vandenberghe, I., De Smet, L., Frishman, D., Nealson, K. H., et al. (2004). Identification of 42 possible cytochrome $c$ genes in the Shewanella oneidensis genome and characterization of six soluble cytochromes. OMICS 8, 57-77. doi: 10.1089/153623104773547499

Miller, D. J., Zhang, Y.-M., Subramanian, C., Rock, C. O., and White, S. W. (2010). Structural basis for the transcriptional regulation of membrane lipid homeostasis. Nat. Struct. Mol. Biol. 17, 971-975. doi: 10.1038/nsmb.1847

Mitchell, A. G., and Martin, C. E. (1995). A novel cytochrome $b_{5}$-like domain is linked to the carboxyl terminus of the Saccharomyces cerevisiae $\Delta-9$ fatty acid desaturase. J. Biol. Chem. 270, 29766-29772. doi: 10.1074/jbc.270.50.29766

Moczydlowski, E. G. (2013). The molecular mystique of tetrodotoxin. Toxicon 63, 165-183. doi: 10.1016/j.toxicon.2012.11.026

Parsons, J. B., and Rock, C. O. (2011). Is bacterial fatty acid synthesis a valid target for antibacterial drug discovery? Curr. Opin. Microbiol. 14, 544-549. doi: 10.1016/j.mib.2011.07.029

Reese, M. G. (2001). Application of a time-delay neural network to promoter annotation in the Drosophila melanogaster genome. Comput. Chem. 26, 51-56. doi 10.1016/S0097-8485(01)00099-7
Stukey, J. E., McDonough, V. M., and Martin, C. E. (1990). The OLE1 gene of Saccharomyces cerevisiae encodes the delta 9 fatty acid desaturase and can be functionally replaced by the rat stearoyl-CoA desaturase gene. J. Biol. Chem. 265, 20144-20149.

Sun, L., Dong, Y., Shi, M., Jin, M., Zhou, Q., Luo, Z. Q., et al. (2014). Two residues predominantly dictate functional difference in motility between Shewanella oneidensis flagellins FlaA and FlaB. J. Biol. Chem. 289, 14547-14559. doi: 10.1074/jbc.M114.552000

Venkateswaran, K., Moser, D. P., Dollhopf, M. E., Lies, D. P., Saffarini, D. A., MacGregor, B. J., et al. (1999). Polyphasic taxonomy of the genus Shewanella and description of Shewanella oneidensis sp. nov. Inter. J. Syst. Bacteriol. 49, 705-724. doi: 10.1099/00207713-49-2-705

Wang, D., Wang, Y., Huang, H., Lin, J., Xiao, D., and Kan, B. (2013). Identification of tetrodotoxin-producing Shewanella spp. from feces of food poisoning patients and food samples. Gut Pathogens 5:15. doi: 10.1186/1757-4749-5-15

Wang, H., and Cronan, J. E. (2004). Functional replacement of the FabA and FabB proteins of Escherichia coli fatty acid synthesis by Enterococcus faecalis FabZ and FabF Homologues. J. Biol. Chem. 279, 34489-34495. doi: 10.1074/jbc.M403874200

Wu, L., Wang, J., Tang, P., Chen, H., and Gao, H. (2011). Genetic and molecular characterization of flagellar assembly in Shewanella oneidensis. PLoS ONE 6:e21479. doi: 10.1371/journal.pone.0021479

Yuan, J., Wei, B., Shi, M., and Gao, H. (2011). Functional assessment of EnvZ/OmpR two-component system in Shewanella oneidensis. PLoS ONE 6:e23701. doi: 10.1371/journal.pone.0023701

Zhang, H., Fu, H., Wang, J., Sun, L., Jiang, Y., Zhang, L., et al. (2013). Impacts of nitrate and nitrite on physiology of Shewanella oneidensis. PLoS ONE 8:e62629. doi: 10.1371/journal.pone.0062629

Zhang, Y.-M., Marrakchi, H., and Rock, C. O. (2002). The FabR (YijC) transcription factor regulates unsaturated fatty acid biosynthesis in Escherichia coli. J. Biol. Chem. 277, 15558-15565. doi: 10.1074/jbc.M201399200

Zhang, Y.-M., and Rock, C. O. (2008). Membrane lipid homeostasis in bacteria. Nat. Rev. Micro. 6, 222-233. doi: 10.1038/nrmicrol839

Zhang, Y.-M., Zhu, K., Frank, M. W., and Rock, C. O. (2007). A Pseudomonas aeruginosa transcription factor that senses fatty acid structure. Mol. Microbiol. 66, 622-632. doi: 10.1111/j.1365-2958.2007.05934.x

Zhu, K., Choi, K.-H., Schweizer, H. P., Rock, C. O., and Zhang, Y.-M. (2006). Two aerobic pathways for the formation of unsaturated fatty acids in Pseudomonas aeruginosa. Mol. Microbiol. 60, 260-273. doi: 10.1111/j.1365-2958.2006.05088.x

Zhu, K., Zhang, Y.-M., and Rock, C. O. (2009). Transcriptional regulation of membrane lipid homeostasis in Escherichia coli. J. Biol. Chem. 284, 34880-34888. doi: 10.1074/jbc.M109.068239

Conflict of Interest Statement: The authors declare that the research was conducted in the absence of any commercial or financial relationships that could be construed as a potential conflict of interest.

Received: 17 November 2014; accepted: 05 December 2014; published online: 22 December 2014

Citation: Luo Q, Shi M, Ren Y and Gao H (2014) Transcription factors FabR and FadR regulate both aerobic and anaerobic pathways for unsaturated fatty acid biosynthesis in Shewanella oneidensis. Front. Microbiol. 5:736. doi: 10.3389/fmicb.2014.00736 This article was submitted to Food Microbiology, a section of the journal Frontiers in Microbiology.

Copyright (c) 2014 Luo, Shi, Ren and Gao. This is an open-access article distributed under the terms of the Creative Commons Attribution License (CC BY). The use, distribution or reproduction in other forums is permitted, provided the original author(s) or licensor are credited and that the original publication in this journal is cited, in accordance with accepted academic practice. No use, distribution or reproduction is permitted which does not comply with these terms. 